\title{
Occupational COVID-19 exposure among health care workers in obstetric unit in a Central Government Hospital in India: initial experience
}

\author{
Neha Pruthi Tandon, Renuka Malik*, Kanika Kumari, Anjali Singh
}

Department of Obstetrics and Gynecology, ABVIMS and Dr. Ram Manohar Lohia Hospital, New Delhi, India

Received: 22 June 2021

Accepted: 16 July 2021

\section{*Correspondence:}

Dr. Renuka Malik,

E-mail: renucam@yahoo.co.in

Copyright: ( ) the author(s), publisher and licensee Medip Academy. This is an open-access article distributed under the terms of the Creative Commons Attribution Non-Commercial License, which permits unrestricted non-commercial use, distribution, and reproduction in any medium, provided the original work is properly cited.

\section{ABSTRACT}

Background: Health care workers (HCW) are the frontline warriors who are at a high risk of acquiring the COVID19. HCW in obstetrical department are at high-risk due to their close proximity with the patient for examination, giving treatment and in delivery. The objectives of this study were to evaluate the positivity rate of COVID-19 in the initial 3 months of pandemic in health care personnel working in obstetric unit in a tertiary care hospital.

Methods: Prospective cohort study was conducted in department of obstetrics and gynecology at tertiary care hospital in Delhi from 10 April to 10 June 2020. Predesigned questionnaire was used to record data of HCWs exposed to COVID-19 patients.

Results: In a period of 3 months (April-June 2020), 152 health care workers were exposed to 30 COVID-19 patients. Out of this, $10 \mathrm{HCW}$ were found to be positive on testing, showing a positivity rate of $6.58 \%$. Positivity ratio was $6: 3: 1$ among nurses, auxiliary workers and doctors respectively. Labor room was area of high infection as $80 \%$ of $\mathrm{HCW}$ were infected in the labor room $.80 \% \mathrm{HCW}$ acquired infection during patient care in hospital and $20 \%$ were infected in contact with asymptomatic COVID-19 positive HCW.

Conclusions: Positivity rate in obstetric department is comparable to that of general population. Appropriate infection prevention measures like use of PPE, handwashing and maintain safe distance from the patient is the key to prevention of infection. Gloves and N95 masks have been shown to provide superior protection as compared to triple layer masks. Nursing staff and auxiliary workers should be reinforced the importance of use of PPE, hand hygiene and physical distancing.

Keywords: Health care workers in obstetric ward, COVID-19 exposure, Positivity rate

\section{INTRODUCTION}

The outbreak of coronavirus disease (COVID-19) first emerged in Wuhan, Hubei Province, China, in December 2019. ${ }^{1-3}$ On 30 January 2020, the WHO declared a public health emergency of international concern. The same day, first case of COVID-19 was reported in India. ${ }^{4}$ India is the most vulnerable country in South Asian region to COVID19 and currently has the largest number of confirmed cases in Asia. ${ }^{5}$ Health care workers $(\mathrm{HCW})$ are the frontline warriors in COVID-19 pandemic. They face an additional occupational risk besides the risk faced by general population. Infection rate in reported health care workers in China, Italy, UK and Spain are 3.8\%, 10\%, 18\% and $26 \%$ respectively. ${ }^{6-9}$

In China, higher infection rate was reported in non-firstline HCWs $(1.4 \%)$ than first-line HCWs $(0.5 \%) .{ }^{10}$ Factors associated with increased risk of infection in $\mathrm{HCW}$ are inadequate Personal protective equipment (PPE), inadequate hand hygiene, work overload, insufficient diagnostic testing and exposure to asymptomatic infected 
patients. ${ }^{11-13}$ The primary route for the spread of COVID19 is thought to be through aerosolized droplets that are expelled during coughing, sneezing, or breathing, but there also are concerns about possible airborne transmission. HCW working in the departments like anesthesia, respiratory medicine eye, ENT, dental are more at risk to corona infection as they are near the airways of infected patients. The procedures performed by anesthetist's like tracheal intubation are aerosol-generating and there is robust evidence of an association transmission of infection during these procedures. ${ }^{14}$

In pregnancy, progesterone increases ventilation by increasing the sensitivity of respiratory center to carbon dioxide as a result the tidal volume and minute ventilation is increased. ${ }^{15}$ A pregnant woman breathes slightly faster and more deeply to exhale more carbon dioxide. Second stage of labor is a crucial event for transmission of infection as the patient hyperventilates and is unable to keep the mask in position. It is not possible for the HCW to maintain distance from the patient during labor. The hyperventilation in pregnancy and labor in obstetric unit might put the health care workers at higher risk of exposure.

There is paucity of literature about exposure risk in HCW in obstetric ward. The aim of the study was to determine the positivity rate of COVID-19 among HCW working in the department of obstetrics in a government hospital in Delhi and to determine the factors associated with increased risk of infection.

\section{METHODS}

This prospective cohort study was conducted in department of obstetrics and gynecology at central government tertiary care hospital in Delhi from April to June 2020. All HCW working in the department of obstetrics and gynecology who came in contact with COVID-19 positive patient/HCW from 10 April to 10 June 2020 were contacted telephonically and variables like age, gender, category of $\mathrm{HCW}$, type of exposure, distance from patient, duration of contact, PPE used were recorded on excel sheet, after obtaining their consent. COVID testing of contact was done by RT-PCR from day 5 to day 10 or earlier if symptomatic or breech in personal protection noted and report was recorded. HCW who were in nonobstetrical departments and whose home contact was positive were excluded from the study. HCW were classified as symptomatic if they had symptoms like fever, chills, malaise, rhinorrhea, nasal congestion, sore throat, myalgia, dizziness, headache, nausea, diarrhea, anosmia, loss of taste.

The following definitions were used for data analysis.

\section{Health care worker}

Any health care worker working in labor room, gynae ward and opd in department of obstetrics and gynecology.
They were further divided into 3 categories as- (a) doctor (resident and PG student); (b) nursing staff; and (c) auxiliary workers.

\section{Source}

Any pregnant patient or HCW with positive RT PCR for corona, both symptomatic and asymptomatic.

\section{Contact}

A contact of a COVID-19 case is any person (in our case HCW) who has had contact with: (a) A COVID-19 symptomatic case within a timeframe ranging from 48 hours before the onset of symptoms of the case to 14 days after the onset of symptoms; (b) HCW who has had contact with any asymptomatic source within a timeframe ranging from 48 hours before the sample was taken to 14 days after the sample was taken, which was reported positive for COVID-19.

Exposure was defined as coming in close contact with a confirmed COVID-19 positive patient or HCW. Close contact includes: (a) providing care for a person who has COVID-19; (b) being within $2 \mathrm{~m}$ of a person with COVID19 for 15 minutes or more, or; (c) having exposure to respiratory secretions from a person with COVID-19 (e.g., being coughed or sneezed on, sharing a drinking glass or utensils).

Positivity rate in obstetrics ward was defined as number of health care workers exposed to patients and each other and subsequently testing positive in 14-days period.

\section{Number of HCW testing positive $\times 100$ Total number exposed}

\section{Statistical analysis}

The data was entered in MS excel spreadsheet and analysis was done using Statistical Package for Social Sciences (SPSS) version 21.0. Categorical variables were presented in number and percentage (\%) and continuous variables were presented as mean $\pm \mathrm{SD}$ and median. Normality of data was tested by Kolmogorov-Smirnov test. If the normality was rejected then non-parametric test was used.

Statistical tests were applied as follows- (a) quantitative variables were associated using independent t test (as the data sets were not normally distributed) between the two groups; (b) qualitative variables were associated using Fisher's exact test; (c) multivariate logistic regression was used to find out significant risk factors of COVID-19. A $p$ value of $<0.05$ was considered statistically significant.

\section{RESULTS}

The index case of labor ward was admitted on 10 April and reported positive on 12 April 2020 following which 30 patients tested positive by RT PCR. All health care 
workers exposed to the COVID positive patients were quarantined and all were tested with RT PCR from day 510 or on the day of developing symptoms at earliest. In a period of three months, 152 health care workers were exposed to COVID-19 patients. 10 health care workers were found to be positive on testing, showing a positivity rate of $6.58 \%$. Out of $10 \mathrm{HCW}$ infected with COVID-19, six were nursing staff $(60 \%)$ and 3 were workers $(30 \%)$. Out of 51 doctors exposed to COVID-19, one tested positive for COVID-19 in a period of 3 months (Figure 1).

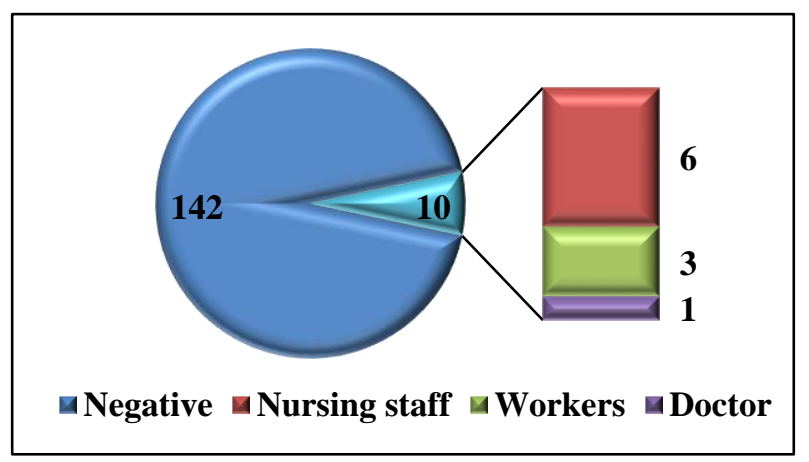

Figure 1: Positivity rate of COVID-19 of $\mathrm{HCW}$.
The mean age of positive and negative HCW was 38 years and 33 years, respectively (Table 1). Nursing Staff comprised a greater proportion of positive employees compared to workers and doctors ( $10 \%$ vs $7 \%$ vs $2 \%) .80 \%$ (8/10) COVID positive HCW were infected in labor room while $20 \%$ were in OPD.

On analysis of safety measure used by HCW to prevent COVID-19 infection, it was seen that $98 \%$ of those who wore PPE, N95 mask, gown and gloves had less chance of getting infected and this difference was statistically significant. It was observed that $80 \%(8 / 10)$ of HCW who got infected were wearing triple layer face mask (Table 2).

On multivariate regression analysis glove and masks were independent protective factors for COVID-19 (Table 3).

All the HCW who tested positive were in close contact with the patient $(<2 \mathrm{~m}) .60 \%$ had a prolonged contact (more than 15 minutes of exposure) with the patient. Also, $80 \%(8 / 10)$ has multiple exposures. However, when data of COVID positive and negative patient was compared in relation to exposure parameters it was not found to be statistically significant. (Table 4).

Table 1: Association of socio-demographic characteristics of HCW with COVID-19 infection.

\begin{tabular}{|c|c|c|c|}
\hline Sociodemographic characteristics & $\begin{array}{l}\text { COVID-19 negative } \\
(\mathrm{N}=142)(\%)\end{array}$ & $\begin{array}{l}\text { COVID-19 positive } \\
(\mathrm{N}=10)(\%)\end{array}$ & $P$ value \\
\hline Age (years) mean \pm SD & $33.44 \pm 7.53$ & $38.7 \pm 11.53$ & 0.189 \\
\hline \multicolumn{4}{|l|}{ Profession N (\%) } \\
\hline Doctor & $51(98.0)$ & 1(2) & \multirow{3}{*}{0.181} \\
\hline Nurse & $52(89.7)$ & $6(10.3)$ & \\
\hline Worker & $39(92.8)$ & $3(7.1)$ & \\
\hline \multicolumn{4}{|l|}{ Place of exposure } \\
\hline Labor room & $112(94.1)$ & $8(5.9)$ & \multirow{3}{*}{0.018} \\
\hline OPD & $3(60)$ & $2(40)$ & \\
\hline Ward & $27(100)$ & 0 & \\
\hline
\end{tabular}

Table 2: Association of use of safety measures with COVID-19 infection.

\begin{tabular}{|lllll|}
\hline Use of safety measures & $\begin{array}{l}\text { No. of exposed HCW } \\
\text { using measures }\end{array}$ & $\begin{array}{l}\text { COVID-19 negative } \\
(\mathbf{N}=\mathbf{1 4 2})(\%)\end{array}$ & $\begin{array}{l}\text { COVID-19 positive } \\
(\mathbf{N}=10)(\%)\end{array}$ & \begin{tabular}{l} 
P value \\
\hline PPE worn
\end{tabular} \\
\hline Mask-N95 & 73 & $72(98.63)$ & $1(1.37)$ & 0.018 \\
\hline Mask- triple layer mask & 77 & $73(98.65)$ & $1(1.35)$ & 0.012 \\
\hline Gown & 62 & $69(89.38)$ & $8(10.39)$ & 0.586 \\
\hline Gloves & 115 & $61(98.39)$ & $1(1.61)$ & 0.048 \\
\hline Face shield & 35 & $112(97.39)$ & $3(2.61)$ & 0.002 \\
\hline Hand hygiene & 147 & $35(100)$ & $0(0)$ & 0.118 \\
\hline
\end{tabular}

Table 3: Multivariate regression analysis to determine best protective equipment.

\begin{tabular}{|llll|}
\hline COVID-19 & Beta coefficient & Odds ratio $(\mathbf{9 5} \%$ CI $)$ & P value \\
\hline PPE worn & -0.654 & $0.520(0.038-7.029)$ & 0.623 \\
\hline Gloves & -3.056 & $0.047(0.006-0.374)$ & 0.004 \\
\hline Gown & -1.587 & $0.204(0.010-4.235)$ & 0.305 \\
\hline N95 & -4.230 & $0.015(0-0.6)$ & 0.026 \\
\hline
\end{tabular}


Table 4: Association of exposure parameters with COVID-19 infection.

\begin{tabular}{|c|c|c|c|}
\hline Exposure parameters & $\begin{array}{l}\text { COVID-19 negative } \\
(\mathrm{N}=142)\end{array}$ & $\begin{array}{l}\text { COVID-19 positive } \\
(\mathrm{N}=10)\end{array}$ & P value \\
\hline \multicolumn{4}{|c|}{ Distance from patient (m) } \\
\hline$<2$ & $137(93.2)$ & $10(6.8)$ & \multirow[b]{2}{*}{1} \\
\hline$>2$ & $5(100)$ & $0(0)$ & \\
\hline \multicolumn{4}{|c|}{ Duration of contact (min) } \\
\hline$<15$ & $112(94.9)$ & $6(5.1)$ & \multirow{2}{*}{0.232} \\
\hline$>15$ & $30(88.2)$ & $4(11.8)$ & \\
\hline \multicolumn{4}{|c|}{ Number of exposure (in times) } \\
\hline 1 & $52(96.3)$ & $2(3.7)$ & \multirow{2}{*}{0.496} \\
\hline$>1$ & $90(91.8)$ & $8(8.2)$ & \\
\hline
\end{tabular}

Of HCW who tested positive, $60 \%$ (6/10) were asymptomatic while $40 \%$ (4/10) were symptomatic. The most common symptoms at the time of survey completion were fatigue $(100 \%)$, headache $(75 \%)$, cough and sore throat $(50 \%)$, and fever and muscle aches $(25 \%)$ Figure 2. Of the $10 \mathrm{HCW}$ who were infected by the working environment in hospital found, $8(80 \%)$ had close contact with confirmed patients and $2(20 \%)$ were exposed to their confirmed colleagues (Figure 3).

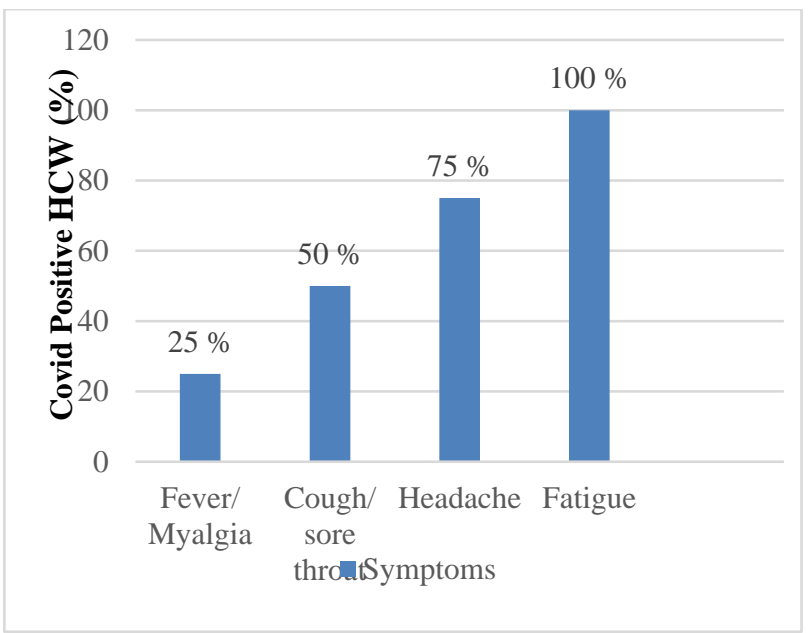

Figure 2: Symptoms in COVID positive symptomatic HCW.

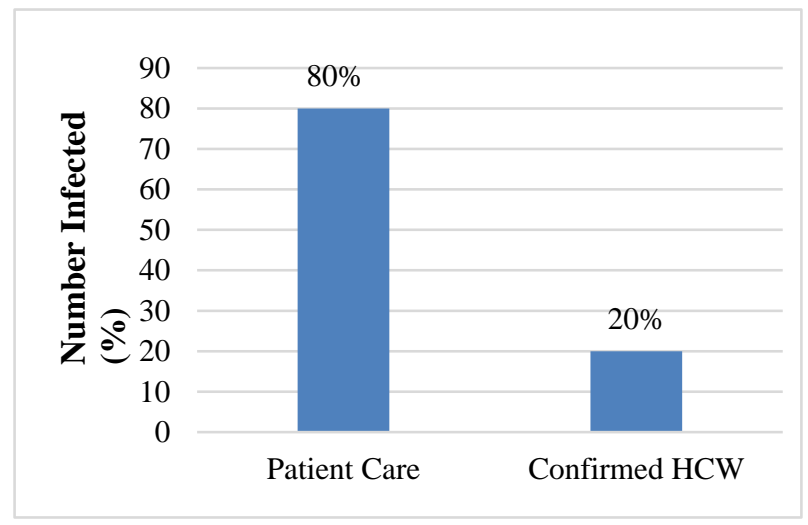

Figure 3: Suspected cause of infection in COVID positive $\mathrm{HCW}$.

\section{DISCUSSION}

COVID-19 infection has challenged the health systems of both developed and developing countries. Health care workers are at a higher risk of acquiring the disease and they can be a source of secondary transmission among patients, family members, and the community. Adequate preventive measures can protect them and the community from this disease.

The first case reported in our department was a case of heart disease with term pregnancy on 10 April 2020, who was asymptomatic and was referred from another government hospital. She developed symptoms on day 2 and subsequently tested positive. This was followed by twenty-nine more patients testing positive in a period of 3 months. Over a period of 3 months rigorous prevention measures have been taken in our hospital to prevent or limit transmission in a health care setting. Standard operating protocols have been developed to avoid any risk to the health care worker.

Our study found $6.58 \%$ positivity rate of COVID-19 in the health care workers in obstetric unit which was similar to that of general population in the initial 3 months of first wave of COVID pandemic. We couldn't find studies on determining positivity rate exclusively in obstetrics and gynaecology department. However, a study by ICMR found 0.82 percent of the total cases in India were health care workers. ${ }^{16}$ A study, published in Lancet found an increased risk of COVID-19 among health care workers as compared to general population. ${ }^{17}$ Study from UK has reported $18 \%$ prevalence of COVID-19 in HCWs. ${ }^{18}$ Infection rate in $\mathrm{HCW}$ in our study was less than that reported in other countries as appropriate preventive measure to control infection spread were taken timely.

We found that $20 \%$ of HCW infected were exposed to an infected co-worker which was similar to study by Zabarsky et al who reported that $25 \%$ of health care personnel got infected after were exposed to an infected patient or co-worker. ${ }^{19}$ In our study, majority of affected HCWs had a mild disease with no ICU stay or mortality. The possible reason for this could be that most of the 
affected HCWs in Obstetric Unit were young adults (mean-38 years) with no associated morbidity.

Infectivity rate in $\mathrm{HCW}$ depends upon virulence of organism, which is very high in COVID-19, immunity of the exposed person (which is difficult to measure) and nature of work. Obstetrical department has unique issues as labor cannot be postponed compared to other medical fields where patient contact and elective surgery can be postponed for a time period. Labor room can be regarded as an aerosol generating area as women during the second stage of labor hyperventilates and it is difficult for a laboring patient to wear mask. During this time, most of the health care workers are in close contact with their patients for an extended duration which puts the health care workers at risk of infection. In our study, $80 \%$ of the health care workers infected were exposed COVID-19 patient in labor room. Higher rate of infection was found among nurses and ancillary workers. Doctors were the least infected in the period of 3 months as all infection prevention precautions were rigorously followed by them. Our results were similar to a study in Tertiary care hospital in China who found higher infection rate in non-first-line HCWs had a (1.4\%) than first-line HCWs $(0.5 \%){ }^{10}$

Study in Wuhan, China retrospectively analyzed risk factors in seventy-two health care workers with COVID19. They found that health personnel working in high-risk department HRD [respiratory department, infection department, intensive care unit (ICU), and surgical department] and with suboptimal hand hygiene after contacting patients had a higher risk of COVID-19. Higher risk with longer duty hours was found, especially in HRD. ${ }^{14}$ In a review of eleven studies by Mhango et al it was found that lack of personal protective equipment, exposure to infected patients, work overload, poor infection control, and pre-existing medical conditions are the major risk factors for COVID-19 among health care workers. ${ }^{20}$ Our study too confirmed that those who were wearing PPE, N-95 mask, gown and gloves were at less risk of COVID-19 infection. Electron microscopy has measured the COVID-19 virus to be between 70-90 nm in diameter. Surgical facemasks provide very little protection for particle sizes 10-80 nm while N95 masks are at least 95\% effective for particle sizes WHO recommends the use of N95 when performing an aerosol generating procedure are performed on the patients. ${ }^{21}$ Our study showed that $\mathrm{HCW}$ wearing triple layer in labor room were at high risk of infection as compared to those wearing N95 mask.

The limitation of our study was that it was a single center short term study. Secondly, we took hospital as high-risk area where as health care workers could have acquired the disease through asymptomatic carriers at home or while commuting which was difficult to exclude. Additional multicentric large studies are needed to confirm our findings. Strength of our study was that it was the first study to access exposure of $\mathrm{HCW}$ in obstetric unit exclusively. We had an acceptable positivity rate in HCW of $6.5 \%$ because of the prompt measures taken by the faculty and administration. At the time when ICMR was suggesting testing of symptomatic patients, we started with mandatory testing for all patients as initially we had all asymptomatic patients testing positive. PPE was provided to all $\mathrm{HCW}$ with periodic evaluation by our microbiology department. We also insisted on mask on patient and absolute restriction of relatives in obstetric unit. A single point entry (triage) for patients and segregation of patients as COVID positive, negative and suspected/unknown category was done. Quick understanding and constant supervision was the reason of low positivity rate.

\section{CONCLUSION}

Positivity rate in obstetrics department is comparable to general public if adequate PPE is worn and COVID-19 appropriate behavior is strictly followed. Appropriate infection prevention measures like use of PPE, handwashing and maintain safe distance from the patient is the key to prevention of infection. N95 masks have been shown to provide superior protection as compared to triple layer.

\section{Recommendations}

Nursing staff and auxiliary workers should be reinforced the importance of use of PPE, hand hygiene and physical distancing.

Funding: No funding sources

Conflict of interest: None declared

Ethical approval: The study was approved by the Institutional Ethics Committee

\section{REFERENCES}

1. Huang C, Wang Y, Li X, Ren L, Zhao J, Ho Y, et al. Clinical features of patients infected with 2019 novel coronavirus in Wuhan, China. Lancet. 2020;395(10223):497-506.

2. Lu H, Stratton CW, Tang YW. Outbreak of pneumonia of unknown etiology in Wuhan, China: the mystery and the miracle. J Med Virol. 2020;92(4):401-2.

3. Hui DS, Azhar IE, Madani TA, Ntoumi F, Kock R, Dar O, et al. The continuing 2019-nCoV epidemic threat of novel coronaviruses to global health - The latest 2019 novel coronavirus outbreak in Wuhan, China. Int J Infect Dis. 2020;91:264-6.

4. Andrews MA, Areekal B, Rajesh KR, Krishnan J, Suryakala R, Krishnan B, et al. First confirmed case of COVID-19 infection in India: A case report. Indian J Med Res. 2020;151:490-2.

5. Mahajan P, Kaushal J. Epidemic Trend of COVID-19 Transmission in India During Lockdown-1 Phase. J Community Health. 2020;45(6):1291-300.

6. Xiao J, Fang M, Chen Q, He B. SARS, MERS and COVID-19 among healthcare workers: a narrative review. J Infect Public Health. 2020;13:843-8. 
7. Lapolla P, Mingoli A, Lee R. Deaths from COVID-19 in healthcare workers in Italy-What can we learn? Infect Control Hosp Epidemiol. 2021;42(3):364-5.

8. Keeley AJ, Evans C, Colton H, Ankcorn M, Cope A, State A, Bennett T, Giri P, de Silva TI, Raza M. Rollout of SARS-CoV-2 testing for healthcare workers at a large NHS Foundation Trust in the United Kingdom, March 2020. Euro Surveill. 2020;25(14):2000433.

9. European centre for disease prevention and cotrol. Rapid risk assessment: Coronavirus disease 2019 (COVID-19) pandemic: increased transmission in the EU/EEA and the UK - eighth update. 2020.

10. Lai X, Wang M, Qin C, Li T, Ran L, Chen D, et al. Coronavirus Disease 2019 (COVID-2019) Infection Among Health Care Workers and Implications for Prevention Measures in a Tertiary Hospital in Wuhan, China. JAMA Network Open. 2020;3(5):209666.

11. Zhou P, Huang Z, Xiao Y, Huang X, Fan XG. Protecting Chinese healthcare workers while combating the 2019 novel coronavirus. Infect Control Hosp Epidemiol. 2020;41(6):745-6.

12. Wang J, Zhou M, Liu F. Reasons for healthcare workers becoming infected with novel coronavirus disease 2019 (COVID-19) in China. J Hosp Infect. 2020;105(1):100-1.

13. Ran L, Chen X, Wang Y, Wu W, Zhang L, Tan X. Risk Factors of Healthcare Workers With Coronavirus Disease 2019: A Retrospective Cohort Study in a Designated Hospital of Wuhan in China. Clin Infect Dis. 2020;71(16):2218-21.

14. Tran K, Cimon K, Severn M, Pessoa SCL, Conly J. Aerosol generating procedures and risk of transmission of acute respiratory infections to healthcare workers: a systematic review. PLoS One. 2012;7(4):35797.
15. Jensen D, Duffin J, Lam YM, Webb KA, Simpson JA, Davies GA, Wolfe LA, et al. Physiological mechanisms of hyperventilation during human pregnancy. Respir Physiol Neurobiol. 2008;161(1):76-86.

16. Chatterjee P, Anand T, Singh KJ, Rasaily R, Singh R, Das $\mathrm{S}$, et al. Healthcare workers \& SARS-CoV-2 infection in India: A case-control investigation in the time of COVID-19. Indian J Med Res. 2020;151(5):459-67.

17. Nguyen LH, Drew DA, Graham MS, Joshi AD, Guo CG, Ma W, Mehta RS, Warner ET, Sikavi DR, Lo $\mathrm{CH}$, Kwon S, et al. Risk of COVID-19 among frontline health-care workers and the general community: a prospective cohort study. Lancet Public Health. 2020;5(9):475-83.

18. Tostmann A, Bradley J, Bousema T, Yiek WK, Holwerda M, Bleeker RC, et al. Strong associations and moderate predictive value of early symptoms for SARS-CoV-2 test positivity among healthcare workers, the Netherlands, March 2020. Euro Surveill. 2020;25(16):2000508.

19. Zabarsky TF, Bhullar D, Silva SY, Mana TSC, Ertle MT, Navas ME, et al. What are the sources of exposure in healthcare personnel with coronavirus disease 2019 infection?. Am J Infect Control. 2021;49(3):392-5.

20. Mhango M, Dzobo M, Chitungo I, Dzinamarira T. COVID-19 Risk Factors Among Health Workers: A Rapid Review. Saf Health Work. 2020;11(3):262-5.

21. WHO. Rational use of personal protective equipment (PPE) for coronavirus disease (COVID-19): interim guidance, 2020. Available at: https://apps.who.int/ iris/handle/10331498. Accessed on 12 June 2021.

Cite this article as: Tandon NP, Malik R, Kumari K, Singh A. Occupational COVID-19 exposure among health care workers in obstetric unit in a Central Government Hospital in India: initial experience. Int J Reprod Contracept Obstet Gynecol 2021;10:3029-34. 